\title{
Trama intertextual de Casmurro
}

\author{
Maura Böttcher Curvello ${ }^{1}$
}

\begin{abstract}
RESUMO: O presente estudo visa indicar como a intertextualidade em Dom Casmurro corrobora a idéia de traição sugerida pela narrativa. A infidelidade ocorre, como se pretende mostrar, na esfera psicológica e literária, o que pode ser inferido com base nas sugestões intertextuais, isto é, no "diálogo" que Machado estabelece com outros textos.
\end{abstract}

ABSTRACT: This essay seeks to show how intertextuality in Dom Casmurro confirms the idea of betrayal suggested by the story. The disloyalty occurs, as this paper intends to demonstrate, in psychological and literary field as can be inferred by intertextual suggestions, namely, the dialog of Machado and other texts.

PALAVRAS-CHAVE: Intertextualidade; Psicologia; Dissimulação; Ironia

KEYWORDS: Intertextuality; Psychology; Dissimultation; Irony

Dom Casmurro tem sido analisado enfatizando-se Capitu e sua complexidade; o foco sobre essa personagem feminina enigmática é uma maneira de o narrador-personagem ofuscar sua personalidade problemática e justificar seu veredicto de ter julgado, condenado e punido a esposa. A obra é composta como um processo judicial, acrescida de conceitos de um ex-seminarista, ou seja, o narrador é duplamente educado na arte de persuadir. Com esse intuito, retrata Capitu como uma pessoa pouco confiável. ${ }^{2}$

Na obra, Capitolina é descrita como uma moça autocontrolada, dissimulada, dona de planos astutos, gananciosa, capaz de ter relações escusas com Escobar, dotada de olhos magnéticos e senhora de beleza e gestos sedutores. Assim, a personalidade e a aparência de Capitu

1 Doutoranda pela Universidade de São Paulo. Tese: As faces de Camilo na dramaturgia contemporânea portuguesa. Contato: maurabc@usp.br

2 Sobre as características de Capitu, os seguintes trechos da obra são relevantes: ASSIS, 1999, pp. 52, 62, 64, 71, 88-89, 114, 162, 190-191, 208. 
ensombram Bentinho e sua aparente ingenuidade, traço reforçado insistentemente, ao comparar-se com Capitu.

Ao tratar de si, Bentinho enfatiza características como ser sonhador, apaixonado, iludido, submisso à mãe e figuras de autoridade, declara ter "olhos longos e constantes" (ASSIS, 1999, p. 64) e apresentase como um ser fraco quando se trata de tomar atitudes que o levariam a atingir seus objetivos (ASSIS, p. 42).

No entanto, o caráter de Bentinho é muito mais intrincado do que ele parece revelar. E é dele que resulta muito da ambigüidade da obra. Pioneiro no que Bakhtin, Kristeva e Barthes julgam ser característica da literatura moderna, a obra de Machado é dialógica ou plural, isto é, uma leitura com múltiplos significados. O narrador-personagem provoca o leitor a participar de maneira ativa, crítica e consciente. A obra machadiana cumpre o preceito de Genette de que literatura é sobretudo recriação (ALLEN, 2000, p. 96). O foco dessa narrativa está no narrador e não na história (o título da obra já sugere esse enfoque). Machado deixa clara sua intenção em dialogar com outros textos, já que cita títulos de obras, trechos, nomes de autores ou de personagens históricas e a relação entre Dom Casmurro e seus intertextos sugere os significados de sua obra.

Pela intertextualidade, Bento sugere para o leitor atento seus traços de caráter. Esse jogo começa a ser instituído no capítulo I pela advertência ao leitor: "Não consultes dicionários. Casmurro não está aqui no sentido que eles lhe dão, mas no que lhe pôs o vulgo de homem calado e metido consigo.” (ASSIS, p. 17) No entanto, o leitor atento não desconsiderará que "casmurro" significa "teimoso, obstinado". Esses traços de personalidade revelam-se desde o objetivo do livro e da reconstrução da casa em que morava na infância, pois revelam a obstinação de Bento pela época em que se considerava feliz. Essa renitência é acentuada no capítulo “Os vermes" em que o protagonista busca em livros "velhos, mortos e enterrados" a cura para seus males.

No Capítulo II, a referência às personagens: César, Augusto, Nero e Massinissa, são outras sugestões dos significados que essa obra pode 
adquirir. Homens poderosos, em sua história, traíram ou foram vítimas de traição. O primeiro foi assassinado por traidores, o segundo, difamado como traidor ainda que injustamente, é obrigado a exilar-se até que possa tomar o poder. Nero foi imperador graças a uma mãe astuta que convence o marido a nomear não o filho dele, mas o dela como herdeiro do trono. No entanto, Nero considera-se sempre alvo de traidores e mata sua própria mãe por essa suspeita. Massinissa oferece veneno à sua esposa cartaginesa a fim de garantir o apoio de Roma ao império númida, de que ele era senhor.

As referências aos imperadores começam a instaurar a ambigüidade da obra, já que essas personagens, parte integrante da casa com que o narrador se identifica, não compõem uma associação homogênea de traidores ou de vítimas, mas um grupo heterogêneo que mescla os dois tipos. Estaria assim o protagonista insinuando que ele pode não ser simplesmente uma vítima, mas também um traidor?

Essa hipótese parece pertinente quando se considera, por exemplo, que Bento se associa, no capítulo XXIX, a Ariosto, autor de Orlando Furioso, obra que apresenta a loucura e a razão como partes integrantes de um mesmo ser. Orlando, apaixonado por Angélica, segue no encalço da moça, passando por inúmeras aventuras, mas ao encontrá-la descobre que não é, nem será nunca amado, do que decorre sua loucura e fúria. O amor é fonte de sentimentos ambíguos: ódio, amor, orgulho, ciúme, valentia, cortesia, covardia, coragem, traição, luxúria, amizade, dedicação. A complexidade da personagem de Ariosto parece relacionar-se a Bento, o qual, obstinado por Capitu, perde a razão e torna-se um juiz inexorável. Pela associação com o intertexto, as aparentes ingenuidade e singeleza de Bentinho começam a desvanecer. Também Santiago apresenta sentimentos contraditórios ${ }^{3}$ que parecem

\footnotetext{
3 "Escapei ao agregado, escapei a minha mãe não indo ao quarto dela, mas não escapei a mim mesmo. Corri ao meu quarto, e entrei atrás de mim. Eu falava-me, eu perseguia-me, eu atirava-me à cama, e rolava comigo, e chorava, e abafava os soluços com a ponta do lençol. Jurei não ir ver Capitu aquela tarde, nem nunca mais, e fazerme padre de uma vez."( ASSIS, pp. 124-125).

"Não ceei e dormi mal. Na manhã seguinte não estava melhor, estava diferente. A minha dor agora complicava-se do receio de haver ido além do que convinha, deixando
} 
corroborar a complexidade sugerida pela alusão aos bustos de imperadores de sua sala.

Nos capitulos XXXII e CXXIX Dante é mencionado. A referência remete a episódio do "Inferno", ao caso de amor adúltero entre Francesca e o irmão de seu marido Gianciotto, que comete fratricídio quando flagra Paolo com sua esposa. Interessante notar que, assim como prevê Bento "Há de dobrar o gozo aos bem-aventurados do céu conhecer a soma dos tormentos que já terão padecido no inferno os seus inimigos", o único consolo de Francesca e Paolo é saber que Gianciotto padecerá mais do que eles em um setor mais cruel nas profundezas do Inferno porque é um assassino. No caso de Bento, envelhecer sozinho, considerando que sua esposa e seu melhor amigo estariam juntos na eternidade parece ser sua condenação, porque acreditar em um renascimento do qual ele sairia renovado ("Rinovellate di novelle fronde.4") é uma grande ironia vindo daquele que afirma:

Pois, senhor, não consegui recompor o que foi nem o que fui. Em tudo, se o rosto é igual, a fisionomia é diferente. Uma certidão que me desse vinte anos de idade poderia enganar os estranhos, como todos os documentos falsos, mas não a mim. (ASSIS, pp. 18 e 19)

No capítulo XXXIII, Bento associa-se a Des Grieux : "Não mofes dos meus quinze anos, leitor precoce. Com dezessete, Des Grieux (e mais era Des Grieux) não pensava ainda na diferença dos sexos.” (ASSIS,p. 66)

A referência é feita com vistas a reforçar o caráter ingênuo de Bentinho; no entanto, considerando a obra do Abade Prévost, percebese que Dom Casmurro retrata Capitu com características próximas as de Manon, amada de Des Grieux, mulher de caráter inconstante,

de examinar o negócio. Posto que a cabeça me doesse um pouco, simulei maior incômodo, com o fim de não ir ao seminário e falar a Capitu. Podia estar zangada comigo, podia não querer-me agora e preferir o cavaleiro. Quis resolver tudo, ouvi-la e julgá-la; podia ser que tivesse defesa e explicação." ( ASSIS, p. 125).

${ }^{4}$ Rinovellate di- novelle fronde. Renovados de face nova. 
interessada em luxo e segurança material, incapaz de decidir entre a segurança proporcionada pelo rico Geronte de Ravoir e a paixão pelo jovem impetuoso, mas pobre, Des Grieux. Geronte descobre a relação entre Manon e Des Grieux e manda a polícia prendê-la e exilá-la como prostituta. O amante segue com a jovem ao exílio, mas ela morre antes do desembarque.

Bento não é, como quer mostrar, sensivel como Des Grieux, parece relacionar-se a Geronte, o homem traído. No entanto, não é esse o retrato que faz de si, representa-se, outrossim, como menino ingênuo.

Procurando ressaltar seu caráter sonhador, em "Uma égua", capítulo XL, Bento declara:

Creio haver lido em Tácito que as éguas iberas concebiam pelo vento, se não foi nele, foi noutro autor antigo, que entendeu guardar essa crendice nos seus livros. Neste particular, a minha imaginação era uma grande égua ibera; a menor brisa lhe dava um potro, que saía logo cavalo de Alexandre (ASSIS, p.77).

Aqui o intertexto é uma figura histórica. Cabe considerarmos algumas particularidades do historiador que possam sancionar alguns traços do protagonista machadiano. Tácito era moralista, um severo juiz de caráter, desprezava o povo comum, amava os discursos inventados ou modificados (intertextuais). As características do historiador reforçam a figura do árbitro insensivel e afastam-no da imagem de ingênuo e sonhador; além disso podem ser consideradas uma alusão metalinguística, pois sugerem o recurso da intertextualidade, já que Tácito também relia e reformulava textos anteriores. Já o cavalo de Alexandre era impetuoso e incontrolável, como a imaginação de Bento, que pode ter inventado o adultério sem nenhuma prova concreta, "concebido de uma brisa".

O capítulo LXII parece fornecer informações a respeito da personalidade de Santiago. No contexto do capitulo, Iago parece, à primeira vista associar-se a José Dias já que este suscita o ciúme de Bentinho. No entanto, José Dias é apenas um agregado bajulador que 
se preocupa em garantir seu quinhão pelos elogios e superlativos. Cabe esquadrinhar as características da personagem de Shakespeare para inferir-se a quem se refere a "ponta de Iago".

Iago é considerado um vilão sinistro porque se apresenta e se faz acreditar como uma pessoa incondicionalmente honesta, enquanto trama contra todos que o rodeiam. Em outros termos, ele concilia seu comportamento manipulador e perverso com a reputação de probidade. Essa ambigüidade o torna a personagem mais intrincada da obra; Shakespeare dedica a ele o maior número de falas. Sua visão de mundo é amarga e cínica; seu egoísmo, frio e calculista, o que parece ter origem em não ter sido promovido por Otelo, isto é, de sentir-se rebaixado, diminuído.

Iago tem a sagacidade de provocar a vítima queixosa, extrair dela o orgulho de superioridade intelectual, levá-la a confissões ridículas e liquidá-la com seu poder de persuasão. Isso porque conhece a psicologia humana ${ }^{5}$ e faz uso desse conhecimento em benefício próprio. Para o espectador, há o Iago digno, revelado pelos diálogos com outras personagens e outro, mesquinho e torpe, que se dá a conhecer quando confessa intenções criminosas. Em Dom Casmurro, no entanto, a

5 IAGO - Mulher tonta não há, sendo bonita, pois sabe arranjar filho e ser catita.[...] IAGO - Que amor lhe tenha Cássio, é o que acredito; que ela o ame, é quase certo e compreensivel. O Mouro, embora eu suportar não o possa, por natureza é firme, nobre e amável, tendo eu plena certeza de que ele há de ser o marido ideal para Desdêmona. Mas eu também a amo, não por simples concupiscência, muito embora eu seja também passível dessa grande falta. Não; é para saciar minha vingança, pois suspeito que o Mouro luxurioso pulou na minha sela, pensamento esse que, como mineral nocivo, me corrói as entranhas, sem que nada possa ou deva deixar-me a alma aliviada antes de virmos nisso a ficar quites: é mulher por mulher. Falhando o plano, farei tal ciúme despertar no Mouro, que não possa curá-lo o raciocínio. Para obter isso - caso este sabujo de Veneza, que à trela sempre trago, saiba encontrar o rasto e correr firme - pegarei Miguel Cássio pelo flanco, pois temo que ele também tenha usado meu gorro de dormir. Assim, o Mouro me amará, ficar-me-á reconhecido, e um prêmio me dará por eu ter feito dele um asno completo, e o ter privado da paz e do sossego, até nas raias ir bater da loucura. Aqui está tudo. Meio confuso, é certo; mas, inteira, nunca se mostra, nunca, a bandalheira. (Sai.) (Fonte:http://www.ebooksbrasil.org/eLibris/otelo.html) 
duplicidade de Bento não é declarada, nem difundida; apenas o caráter ingênuo e inocente do protagonista é divulgado com insistência. A face tirana, opressora, insensivel, de Bento só pode ser inferida pelas sugestões intertextuais e informações sutis, como, por exemplo, o sobrenome da personagem, Santiago: "Santo" + "Iago". Insinua-se, assim, a característica fundamental de Bento, a ambigüidade anjo $\mathrm{x}$ demônio que há em sua personalidade, como temos procurado mostrar pela interpretação dos intertextos.

A insensibilidade de Bento teria sido gerada por sua obstinação por Capitu e pela consciência de seu papel social. Como burguês do século XIX, tem consciência de que deve ser o patriarca, responsável pelas finanças, organizador de planos e projetos, autocontrolado, racional. Entretanto, com a maturidade começa a perceber que essas são características de Capitu, ele foi sempre o jovem sonhador, que gastava desnecessariamente, embaraçava-se diante de situações constrangedoras e elaborava planos falhos. Saber-se menos hábil que a esposa parece dar origem a um novo sentimento: a inveja destruidora. Por desejar possuir as qualidades de Capitu, o protagonista torna-se cada vez mais egocêntrico a fim de enfocar a si em detrimento da moça. O desejo de auto-afirmação e a necessidade de ser o mais forte (darwinismo social) fazem com que Bento crie motivos para eliminar a esposa.

Diferentemente de Iago que engana os demais, mas previne-se contra sua malevolência ${ }^{6}$, Santiago, ao condenar a amada, trai a si mesmo e torna-se "casmurro". O protagonista machadiano parece seguir conhecimentos de Iago e os utilizar contra Capitu.

6 IAGO - Tão certo como eu ser um homem honesto, pensei que houvesses recebido algum ferimento no corpo; há mais prejuízo nisso do que na reputação. A reputação é um apêndice ocioso e enganador; obtido, muitas vezes, sem merecimento, e perdido sem nenhuma culpa. (Fonte:http://www.ebooksbrasil.org/eLibris/otelo.html) 
Bento julga, condena e exila a esposa, mas jamais torna o caso público. Para preservar a reputação diante da opinião pública - o que é vital na sociedade burguesa, vai à Europa algumas vezes e diz aos amigos ter visitado a esposa e o filho.

Essa condenação torna-se motivo de Santiago terminar o "soneto de sua vida" 7 com o verso: "Perde-se a vida, ganha-se a batalha!" (ASSIS, p. 18) e de confessar: "Se só me faltassem os outros, vá um homem consola-se mais ou menos das pessoas que perde; mais falto eu mesmo, e esta lacuna é tudo." (ASSIS,p.97). O protagonista machadiano incorpora Iago de tal forma que ilude a si mesmo, mas não se acautela do ciúme, como sarcasticamente propõe a personagem de Shakespeare8:

IAGO - Acautelai-vos, senhor, do ciúme; é um monstro de olhos verdes, que zomba do alimento de que vive. Vive feliz o esposo que, enganado, mas ciente do que passa, não dedica nenhum afeto a quem lhe causa o ultraje. Mas que minutos infernais não conta quem adora e duvida, quem suspeitas contínuas alimenta e ama deveras!

A conduta de Bento parece envenená-lo, tornando-o casmurro, prejudicar Capitu, que morre distante, e confundir o leitor, incapaz de saber se houve ou não o adultério9.

A traição adquire, com isso, um novo sentido. Alterando o procedimento tipicamente realista de tematizar o adultério, Machado

7 No capitulo LV "Um soneto", Bento parece sugerir pelo poema que jamais soube completar a síntese de sua vida: o início feliz: "Oh! flor do céu! oh! flor cândida e pura!" e a opção final, ou " Perde-se a vida, ganha-se a batalha!" ou "Ganha-se a vida, perde-se a batalha!"

8 Fonte: http://www.ebooksbrasil.org/eLibris/otelo.html

9 Essa indeterminação é validada, sobretudo, pela conduta de um narrador em primeira pessoa que apresenta provas e contraprovas a seu caso. Uma contraprova evidente é sugerida em: "No intervalo, evocara as palavras do finado Gurgel, quando me mostrou em casa dele o retrato da mulher, parecido com Capitu. Hás de lembrarte delas; se não, relê o capítulo, cujo número não ponho aqui, por não me lembrar já qual seja, mas não fica longe. Reduzem-se a dizer que há tais semelhanças inexplicáveis... Pelo dia adiante, e nos outros dias, Ezequiel ia ter comigo ao gabinete, e as feições do pequeno davam idéia clara das do outro, ou eu ia atentando mais nelas." (ASSIS, p. 200) 
parece abordar a capacidade de o ser humano criar intrigas para eliminar aquele que lhe constitui uma ameaça.

Além da associação entre Bento e Iago, outras podem ser inferidas. Capitu, por exemplo, parece identificar-se com Desdêmona. A única defesa da protagonista machadiana às acusações de Bento assemelha-se à de Desdêmona quando responde à declaração de Otelo de que ela seria adúltera: "O céu sabe de tudo."10.

\section{Em Dom Casmurro,}

[...]Capitu olhou para mim com desdém, e murmurou: // -- Sei a razão disto; é a casualidade da semelhança... A vontade de Deus explicará tudo... Ri-se? É natural- apesar do seminário não acredita em Deus; eu creio... Mas não falemos nisto; não nos fica bem dizer mais nada. (ASSIS, p. 199).

Interessante notar que a obra machadiana parece dialogar com a peça em diferentes níveis e colocar em pauta procedimentos estilísticos. É o que ocorre pela alusão a Otelo no capítulo LXXII:

Nesse gênero [dramático] há porventura alguma cousa que reformar, e eu proporia, como ensaio, que as peças começassem pelo fim. Otelo mataria a si e a Desdêmona no primeiro ato, os três seguintes seriam dados à ação lenta e decrescente do ciúme, e o último ficaria só com as cenas iniciais da ameaça dos turcos, as explicações de Otelo e Desdêmona, e o bom conselho do fino Iago: "Mete dinheiro na bolsa." Desta maneira, o espectador, por um lado, acharia no teatro a charada habitual que os periódicos lhe dão, por que os últimos atos explicam o desfecho do primeiro, espécie de conceito, e, por outro lado, ia para a cama com uma boa impressão de ternura e de amor (ASSIS,p. 122).

A inversão proposta à cronologia da peça modificaria o sentido do texto, alterando a visão do espectador acerca do enredo. No contexto de Otelo, a fala de Iago transcrita dirige-se a Rodrigo e tem por objetivo persuadir o rapaz a seduzir Desdêmona com seu dinheiro e, assim, trair Otelo. Iago pretende prejudicar Otelo e tomar para si o dinheiro do meliante. 
Se a peça fosse alinear, o conselho de Iago não seria seguido do roubo dos bens de Rodrigo e ludibriaria o entendimento de alguns espectadores. A acronologia seria, então, uma forma de embuste. Em Dom Casmurro esse é um dos procedimentos estilísticos utilizados, o que sugere que a estrutura da história machadiana poderia levar ao dolo.

Dom Casmurro é elaborado como um processo judicial em que o advogado Bento Santiago exporia as provas do adultério de Capitu e justificaria tê-la condenado ao exílio. Para isso, o protagonista recorre ao conhecimento adquirido no seminário. Embora esses estudos não tenham despertado a fé em Bento, eles lhe são úteis para apresentar/esconder sua personalidade, enquanto exibe provas condenatórias do adultério de Capitu. A citação do livro do Eclesiástico com que termina a obra tem a intenção de advertir os homens para que se precavejam diante das artimanhas femininas: "Jesus, filho de Sirach, se soubesse dos meus primeiros ciúmes, dir-me-ia, como no seu cap. IX, vers. 1: 'Não tenhas ciúmes de tua mulher para que ela não se meta a enganar-te com a malícia que aprender de ti'.” (ASSIS, p. 209) . Essa é uma maneira de corroborar sua visão acerca de Capitu e sua capacidade de traí-lo.

Resta saber se o egoísmo de Bento é produto da soma da paixão avassaladora com a obrigação social de ser o patriarca, ou se é um traço de sua personalidade. O trecho em que o narrador analisa sua conduta implacável diante da esposa e do filho que tanto amara parece elucidar a questão:

Contava com a minha debilidade ou com a própria incerteza em que eu podia estar da paternidade do outro, mas falhou tudo. Acaso haveria em mim um homem novo, um que aparecia agora, desde que impressões novas $e$ fortes $o$ descobriam? Nesse caso era um homem apenas encoberto. Respondi-lhe que ia pensar, e fariamos o que eu pensasse. Em verdade vos digo que tudo estava pensado e feito. (ASSIS, p. 200. Grifo nosso.) 
A consciência de Bento de que sempre fora um homem firme e inabalável mostra o egocentrismo como uma característica de sua personalidade e essa interpretação é validada quando se verifica como o menino Bento procedia na infância:

Tinha eu de treze para quatorze anos. Da segunda vez que o vi ali, como falássemos da guerra da Criméia, que então ardia e andava nos jornais, Manduca disse que os aliados haviam de vencer, e eu respondi que não. // [...] // Naturalmente, iamos com o que nos diziam os jornais da cidade transcrevendo os de fora, mas pode ser também que cada um de nós tivesse a opinião do seu temperamento. Fui sempre um tanto moscovita nas minhas idéias. (ASSIS, p. 140. Grifo nosso.)

Ser "um tanto moscovita nas idéias" significa, no contexto da época, apoiar o então czar russo Nicolau I. Esse imperador instaurou um governo absolutista contrário a quaisquer movimentos nacionalistas e liberais. Chamado de "O Czar de Ferro", foi um "tirano execrável" em O Profeta (data desconhecida) ${ }^{11}$ cujo longo governo (1825-1855) foi tido como um Reino das Trevas ${ }^{12}$. Assim, Bento é figurado como um déspota, opressor, sempre desconfiado de traidores, exigindo fidelidade e obediência de seus "súditos". Essa imagem é restabelecida nos trechos em que Santiago evidencia que seu ciúme incontrolável:

[...] Venho explicar-te que tive tais ciúmes pelo que podia estar na cabeça de minha mulher, não fora ou acima dela. É sabido que as distrações de uma pessoa podem ser culpadas, metade culpadas, um terço, um quinto, um décimo de culpadas, pois que em matéria de culpa a graduação é infinita. A recordação de uns simples olhos basta para fixar outros que os recordem e se deleitem com a imaginação deles. Não é mister pecado efetivo e mortal, nem papel trocado, simples palavra, aceno, suspiro ou sinal ainda mais miúdo e leve.[...] (ASSIS, p. 163)

Por falar nisto, é natural que me perguntes se, sendo antes tão cioso dela, não continuei a sê-lo apesar do filho e dos anos. Sim, senhor, continuei. Continuei, a tal ponto que o menor gesto me afligia, a mais infima palavra, uma insistência qualquer; muita vez só a indiferença bastava. Cheguei a ter ciúmes de tudo e de todos. Um vizinho, um par de valsa, qualquer homem, moço

${ }^{11}$ Fonte: http://educaterra.terra.com.br/voltaire/mundo/2005/03/24/000.htm 12 SCHILLING, Voltaire. História. Fonte:

http://educaterra.terra.com.br/voltaire/mundo/2005/03/02/000.htm. 
ou maduro, me enchia de terror ou desconfiança. É certo que Capitu gostava de ser vista, e o meio mais próprio a tal fim (disse-me uma senhora, um dia) é ver também, e não há ver sem mostrar que se vê. (ASSIS, p. 171)

Sendo tão consciente de sua personalidade seria possivel que Bento não condenasse sua desconfiança e seu ciúme avassalador? $\mathrm{O}$ capítulo LXXIII parece revelar informações a esse respeito. No segundo parágrafo, Bento associa-se a Asaverus e considera o ciúme sua condenação, afirmando que isso seria obra do Destino. Ahasverus foi condenado a vagar pela eternidade por ter desprezado e maltratado Jesus no dia do suplício ${ }^{13}$. Ele representa o homem estrangeiro, sem pátria, sem família, abandonado à eterna solidão. Na cena descrita no primeiro transcrito, Asaverus, ao ouvir a trombeta do juízo final, receberia essa condenação. Escrever o livro e reconstruir a casa onde morara na infância são atitudes desesperadas de um estrangeiro, sem família, condenado a vagar sem ter com quem se identificar. Exilar Capitu significa perder a própria identidade, pois a consciência de amar Capitu corresponde ao nascimento de Bento.

Como se pôde perceber, a intertextualidade é um meio de Machado abrir sua obra para várias possibilidades de leitura, tornandoa plural. Não se trata, portanto, de avaliar um caso de adultério, como uma obra realista unívoca (monológica) apresentaria, mas de analisar fatos sociais e psicológicos, sobretudo, a profundidade do ser humano que cria armadilhas para si mesmo. Isso ocorre não apenas com Bento Santiago, todas as personagens podem ser interpretadas de maneiras diferentes. Uma interpretação de Capitu, por exemplo, poderia basearse no fato de a protagonista ser responsável, de alguma forma, pela própria condenação, pois ela é quem aponta a um marido ciumento a semelhança entre a expressão do olhar de seu filho e do finado Escobar (ASSIS, p.190).

13 Câmara, H. Fonte: http://www.hcamara.com.br/atualidades30.htm. 
Pela intertextualidade, Machado não repete o que já foi dito e o que já foi lido, porque não cita apenas, mas de fato atribui novos sentidos às obras com que se dialoga. Se Iago, em Otelo, é complexo por ter duas faces: uma pública e outra privada, mais intrincado é Bento, cuja duplicidade torna-se motivo de sua própria condenação à solidão, à casmurrice. Trair adquire, assim, outros significados que vão além da infidelidade ao casamento, abarca a psicologia de personagens complexas que desejando sobrepor-se às demais, acabam condenandose à solidão.

\section{Referência Bibliográficas:}

ALLEN, Graham. Intertextuality. London and New York: Routledge Taylor and Francis Group, 2000.

ASSIS, Machado de. Dom Casmurro.São Paulo: FTD, 1999.

BARROS, Diana Luz Pessoa de et FIORIN, José Luiz (orgs.). Dialogismo, Polifonia, Intertextualidade. São Paulo: EDUSP, 2003.

MOISÉS, Leyla Perrone-. Texto, critica, escritura. São Paulo: Martins Fontes, 2005. 